\title{
Effect of industrial processing on the IgE reactivity of three commonly consumed Moroccan fish species in Fez region
}

Laboratory of Bioactive Molecules (LMBSF), University Sidi Mohamed Ben Abdellah, Faculty of Sciences and Techniques, Fez, Morocco

\section{KEY WORDS}

allergenicity; fish products; human IgE; rabbit IgG; industrial

processing

\section{Corresponding author}

Lotfi Aarab

Laboratory of Bioactive Molecules

Faculty of Sciences and Techniques

P.O. Box 2202, Road of Immouzer, Fez,

Morocco

Phone: +212663535661

Fax: +212535608214

E-mail: aarablmbsf@gmail.com

Doi

10.23822/EurAnnACI.1764-1489.61

\begin{abstract}
Summary
Objectives. The aim of this work was to study the effect of industrial processing on the allergenicity of three commonly consumed Moroccan fish species in Fez region (sardine, common pandora, and shrimp). Methods. This work was conducted by a sera-bank obtained from 1248 patients recruited from Fez Hospitals. Their sera were analyzed for specific IgE binding to raw fish extracts. Among them, 60 patients with higher specific IgE levels were selected, and used to estimate the binding variation of IgE to these products under several processing (frying, cooking, canning, marinade, and fermentation) using ELISA analysis. Results. ELISA results demonstrated that all the studied processing cause a reduction in the immunoreactivity of human IgE to fish products, with a high action with marinade and fermentation compared to other processing. This alteration was also observed with rabbit IgG in all processed products, showing that the maximum reduction was marked in fermented sardine with $64.5 \%$, in cooked common pandora with 58\%, and in fermented shrimp with 69.2\%. Conclusion. In conclusion, our study has shown that the allergenicity of the three studied fish could be reduced by different industrial processes with different degrees.
\end{abstract}

\section{Introduction}

Fish and shellfish are important foods in the world, including Morocco. Thus, fish and shellfish play an important role in human nutrition and health. They are a valuable source of proteins, physiologically active substances such as eicosapentaenoic acid and docosahexaenoic acid, and minerals such as calcium. However, fish and shellfish mediated by immunoglobulin E (IgE) are becoming a serious problem worldwide, especially in coastal regions (1-4). In Morocco, previous works by our laboratory showed that $9.5 \%$ of 2802 children, aged between 12 and 18 years, reported an allergy to fish and shellfish (5).

Among the various allergens characterized in fish and shellfish, parvalbumin $(12-13 \mathrm{kDa})$, a calcium-binding muscle protein, has been identified as the major fish allergen (6-8), while tropomyosin
(35-38 KDa), a myofibrillar protein, has been recognized as the major shellfish allergen (9-11). Several researches have demonstrated that food processing techniques may induce changes in protein conformation, which may thus affect allergenicity if the allergen epitopes are modified by the process (12-15). Fish and shellfish are subjected to a wide variety of processes, such as thermal (cooking, frying), freezing, canning, salting, drying and fermentation, any of which might reduce or increase their allergenicity.

In the present study, fresh and processed fish (fried, cooked, canned, marinated, and fermented products) have been studied. The aim of this work was to study the effect of industrial processing on the allergenicity of three commonly consumed Moroccan fish species in Fez region (sardine, common pandora, and shrimp). The effects of processing on the allergenicity of these 
products have been analyzed by measuring $\operatorname{IgE}$ binding in sera from patients with high raw fish-specific IgE levels, using ELISA.

\section{Materials and methods}

\section{Fish samples}

Samples of three commonly consumed fish species (sardine, common pandora, and shrimp), fresh and processed, were purchased from various local stores in the city of Fez. The whole fish was rinsed briefly with distilled water. The raw, fried, cooked, canned, marinated and fermented muscle extracts of the 3 fishes were prepared, and each extract was tested by IgEand IgG-ELISA with patient's sera.

\section{Preparation of fish extracts}

\section{Preparation of sardine and common pandora extracts}

The raw extract of each fish was prepared as previously described $(16,17)$. Briefly, fish muscles were defatted with chloroform $(20 \%)$ to remove lipids. After filtration, the powder was dried overnight at room temperature. $10 \mathrm{~g}$ of samples were subsequently extracted in $100 \mathrm{ml}$ of phosphate buffer solution (PBS) ( $\mathrm{pH} 7.4)$ for $12 \mathrm{~h}$ at $4{ }^{\circ} \mathrm{C}$. The mixture was then centrifuged at $3000 \mathrm{rpm}$ for $15 \mathrm{~min}$, and the supernatant was filtered and stored at $-20^{\circ} \mathrm{C}$ until use. Quality of extracted proteins was evaluated by sodium dodecyl sulphate polyacrylamide gel electrophoresis (SDS-PAGE).

Each fish species was fried with vegetable oil for $5 \mathrm{~min}$ and subsequently placed on filter paper to remove oil. The cooked fish extract was prepared by boiling fish in water for $10 \mathrm{~min}$. Marinade fish was prepared with olive oil, lemon juice, salt, pepper and garlic for 3 days at $4^{\circ} \mathrm{C}$. Canned sardine was purchased from national markets. The last group of fermented fish occurred by natural fish flora; the fishes were mixed with salt and then fermented for two weeks. All these fish samples were extracted as described above with raw extracts.

\section{Preparation of shrimp extracts}

The raw shrimp extracts were prepared as previously described (18). Briefly, shrimp muscle $(5 \mathrm{~g})$ was incubated in $50 \mathrm{ml}$ of extraction buffer $(1 \mathrm{~mol} / \mathrm{L} \mathrm{KCl}$ and $0.5 \mathrm{mmol} / \mathrm{L} \beta$-mercaptoethanol, $\mathrm{pH}$ 7.0) for $16 \mathrm{~h}$ at room temperature. Supernatants were collected by centrifugation $\left(12,000 \mathrm{xg}, 15 \mathrm{~min}, 4^{\circ} \mathrm{C}\right)$ and stored at $-20^{\circ} \mathrm{C}$ until use. Quality of extracted proteins was evaluated by SDS-PAGE.

Concerning industrial processing of shrimp, samples were subjected to different treatments including frying with vegetable oil (for $3 \mathrm{~min}$ ), cooking/boiling in water (for $5 \mathrm{~min}$ ), marinade with olive oil, lemon juice, salt, pepper and garlic (for a day at $4{ }^{\circ} \mathrm{C}$ ), and fermentation "shrimp paste", which it is primarily made from finely crushed shrimp mixed with salt, and then fermented for several weeks. Shrimp paste was purchased from national markets. The samples $(5 \mathrm{~g})$ were extracted, immediately after processing, in $50 \mathrm{ml}$ of extraction buffer and centrifuged as above (raw extracts). All the extracts were preserved at $-20^{\circ} \mathrm{C}$ for further experiments.

\section{SDS-PAGE analysis}

Protein samples $(100 \mu \mathrm{l}$ per well) were mixed with loading buffer $(10 \%$ SDS, $10 \%$ glycerol, $10 \% \beta$-mercaptoethanol, and $2.5 \%$ bromphenol blue), heated at $100{ }^{\circ} \mathrm{C}(5 \mathrm{~min})$, electrophoresed in $15 \%$ analytical SDS-polyacrylamide gels, and resolved by SDS-PAGE. Proteins were stained using Coomassie Brilliant Blue R-250.

\section{Human sera}

The study was conducted on a sera-bank, with data obtained from 1248 patients recruited in Fez city from the University Hospital Centre and from Fez laboratory. It should be noted that these patients chosen at random were coming from different medical tests. Only patients under anti-allergic treatments were excluded. A questionnaire was provided to all patients concerning food allergy characteristics and fish allergies in particular. Patients were asked to provide information on the presence of allergic symptoms and about their family allergy history. This work was conducted from May 2014 to June 2015, and was approved by the Ethic committee of the University Hospital Center of Fez. After formal consent of the patients, a blood sample of $3 \mathrm{ml}$ was collected in a dry tube. After centrifugation at $3000 \mathrm{rpm}$ during $5 \mathrm{~min}$, sera were separated and stored at $-20^{\circ} \mathrm{C}$ until use.

\section{ELISA analysis}

Among 1248 patients, 1008 were analyzed for specific IgE to sardine. From the 1008 patients, 500 have been analyzed for specific IgE to common pandora. In parallel, 260 patients (from 1008 ) and other 240 patients were analyzed for specific $\operatorname{IgE}$ to shrimp. Among each group, 20 patients with high specific IgE levels (> $80 \mathrm{IU} / \mathrm{ml})$ to raw fish extracts were selected, and used to estimate the binding variation of $\mathrm{IgE}$ to processed fish extracts using enzyme-linked immunosorbent assay (ELISA).

Specific IgE binding to raw and processed fish was assayed by Indirect ELISA as previously described (16-20). Briefly, $100 \mu \mathrm{l}$ of fish protein extracts $(0.5 \mathrm{mg} / \mathrm{ml})$ was deposited per well in 96 well microplates and incubated for $60 \mathrm{~min}$ at $37^{\circ} \mathrm{C}$. Then, 200 $\mu \mathrm{l}$ of $0.5 \%$ bovine serum albumin (BSA) was added to every well for an hour at $37^{\circ} \mathrm{C}$. After removal of BSA, human sera were added $(100 \mu \mathrm{l} /$ well) before incubation with goat anti human $\operatorname{IgE}$ peroxidase conjugate for $60 \mathrm{~min}$ at $37^{\circ} \mathrm{C}$. Bending of anti-IgE was revealed by adding $100 \mu \mathrm{l}$ of $0.05 \%$ OPD (orthophenylene- 
diamine). The reaction was stopped by adding $\mathrm{HCl} 3 \mathrm{M}$. Then the developed color was measured by absorbance at $490 \mathrm{~nm}$.

\section{Preparation of polyclonal antibodies against fish and shellfish extracts}

To study the immunoreactivity of $\operatorname{IgG}$ antibodies to sardine, common pandora and shrimp extracts, rabbit IgGs were prepared against native fish and shellfish extracts (sardine, common pandora and shrimp). These antibodies were obtained after repetitive immunization of rabbits against the native fish and shellfish extracts, using Freund adjutants as described before $(16-18,20)$. After one month, the animals were sacrificed, and blood samples were collected in dry tubes and sera were separated. Then, sodium azide $0.1 \%$ was added to the sera and frozen at $-20^{\circ} \mathrm{C}$ until use.

\section{Statistical analysis}

Descriptive statistics were presented as numbers with percentages or as average values. Statistical analysis was based on the student's t-test taking $\mathrm{p}<0.05$ as the limit of the significant value.

\section{Results}

\section{Sample description}

In our study, we observed that the self-reported food adverse reactions in 1248 patients were $10.3 \%$. Regarding the results of allergy to fish and shellfish, we noticed a strong sensitivity of this population to the fish products (7.5\%). From the 7.5\% $(\mathrm{n}=93)$ who reported fish/shellfish allergy, we noted that the prevalence according to sex was higher in female $(75 \%)$ than in male $(25 \%)$, and $35.5 \%$ of them have an allergic history in their family. From this sensitive population, the most frequent clini- cal signs were cutaneous reactions (75.3\%), followed by gastrointestinal reactions (25.8\%), and respiratory symptoms (9.7\%). Regarding the allergic self-reported reactions in relation to the different food processing in our study population, we observed that fried fish/shellfish (91\%) was the most frequently reported, followed by cooked (67\%) and canned fish/shellfish (39\%).

\section{Specific IgE of patients}

For sardine, sera of 1008 patients have been tested for specific IgE binding to sardine, and the results showed that $27.3 \%$ $(275 / 1008)$ of patients exhibited levels more than $80 \mathrm{IU} / \mathrm{ml}$. From these sensitive patients, we have selected 20 persons (10 children: 5 female, 5 male; 10 adults: 9 female, 1 male) demonstrating high specific IgE to raw sardine with an average value of $199.79 \mathrm{IU} / \mathrm{ml}$, varying between 103.17 to $330.67 \mathrm{IU} / \mathrm{ml}$.

For common pandora, sera of 500 patients have been analyzed for specific IgE binding to common pandora. The results indicated that $25.6 \%$ of patients $(128 / 500)$ presented IgE values higher than $80 \mathrm{IU} / \mathrm{ml}$, of which $11 \%(55 / 500)$ had cross-reactivity with sardine. From them, we have selected 20 persons (5 children: 2 female, 3 male; 15 adults: 12 female, 3 male) displaying high $\mathrm{IgE}$ reactivity to raw common pandora with an average value of $121.54 \mathrm{IU} / \mathrm{ml}$, varying between 80.25 and $289.42 \mathrm{IU} / \mathrm{ml}$.

For shrimp, the dosage of specific IgE to shrimp in 500 patients has shown that $20 \%$ of patients $(100 / 500)$ presented $\mathrm{IgE}$ values higher than $80 \mathrm{IU} / \mathrm{ml}$, of which 3\% (8/260) had cross-reactions to sardine-specific IgE. Among this group, we have selected 20 persons ( 3 children: 2 female, 1 male; 17 adults: 15 female, 2 male) demonstrating high specific IgE to raw shrimp with an average value of $173.79 \mathrm{IU} / \mathrm{ml}$, varying between 136.5 and $220.67 \mathrm{IU} / \mathrm{ml}$. Distribution of specific IgE levels to raw extracts of the three fish species among the studied population (20 per group) is summarized in table $\mathbf{I}$.

Table I - Distribution of specific IgE Levels to raw extracts of 3 fish species among the studied population.

\begin{tabular}{|c|c|c|c|c|c|c|}
\hline \multirow[t]{2}{*}{ Demographic variable } & \multicolumn{2}{|c|}{$\begin{array}{l}\text { Sardine-specific } \\
\text { IgE levels; } \mathrm{n}=20\end{array}$} & \multicolumn{2}{|c|}{$\begin{array}{c}\text { Common pandora- } \\
\text { specific IgE levels; } n=20\end{array}$} & \multicolumn{2}{|c|}{$\begin{array}{l}\text { Shrimp-specific } \\
\text { IgE levels; } \mathrm{n}=20\end{array}$} \\
\hline & $80-150 \mathrm{IU} / \mathrm{ml}$ & $>150 \mathrm{IU} / \mathrm{ml}$ & $80-150 \mathrm{IU} / \mathrm{ml}$ & $>150 \mathrm{IU} / \mathrm{ml}$ & $80-150 \mathrm{IU} / \mathrm{ml}$ & $>150 \mathrm{IU} / \mathrm{ml}$ \\
\hline All & 3 & 17 & 17 & 3 & 2 & 18 \\
\hline \multicolumn{7}{|l|}{ gender } \\
\hline female & 2 & 12 & 12 & 2 & 1 & 16 \\
\hline male & 1 & 5 & 5 & 1 & 1 & 2 \\
\hline \multicolumn{7}{|l|}{ age } \\
\hline children $(<20$ years $)$ & 1 & 9 & 4 & 1 & 1 & 2 \\
\hline adults (> 20 years) & 2 & 8 & 13 & 2 & 1 & 16 \\
\hline
\end{tabular}




\section{Effect of industrial processing on fish proteins using SDS-PAGE analysis}

Protein profiles of raw and processed fish protein extracts were analyzed by SDS-PAGE. As shown in figure 1, SDS-PAGE profile of sardine and common pandora proteins showed a dark band, corresponding to parvalbumin (PV) at approximately $12 \mathrm{KDa}$, which is considered to be the major allergen in fish. These were equally prominent in fried and in cooked extracts. The migration of canned extract indicated loss of definable PV bands with smear profile, suggesting probably a degradation of proteins (A, lane 5), while the PV bands disappeared completely in all fermented extracts (A, B, lane 6$)$ as well as in all marinated extracts (A, lane 7; B, lane 5).

Additional protein bands were seen in the raw sardine at 34,36 and $40 \mathrm{KDa}$ (A, lane 2). Under processing, the $36-\mathrm{KDa}$ band was observed only in fried and cooked sardine extracts, while the 34 and $40 \mathrm{KDa}$ bands disappeared and faded away in all processed sardine extracts. The raw common pandora showed several additional bands between 14 and $45 \mathrm{KDa}$. These bands were also seen in fried extract, but some new minor bands appeared at about $34 \mathrm{KDa}$ in fried pandora extract. The cooked extract displayed approximately at $34-36 \mathrm{KDa}$ a much more prominent band in comparison to the raw and fried extracts. Besides, some new minor bands ranging from 20 to $34 \mathrm{KDa}$ appeared in cooked extracts. Contrarily, no protein band appeared in marinated and fermented common pandora.

Concerning SDS-PAGE profile of shrimp proteins, tropomyosin (TP), considered the shellfish major allergen, appeared at 36-38
$\mathrm{kDa}$. This band was also observed in fried and cooked shrimp extracts, while no TP bands were visible in marinated and fermented extracts. Additional minor protein bands were observed in the raw shrimp at approximately $55 \mathrm{KDa}$ and at $>66 \mathrm{KDa}$. Under frying and cooking processing, the $>66 \mathrm{KDa}$ band was seen only in the fried extract, while the $55 \mathrm{KDa}$ band faded away in the fried and in the cooked extracts. These bands disappeared completely when shrimp was marinated or fermented.

\section{Effect of industrial processing on the detection of fish proteins ex-} tracts by rabbit IgG using ELISA

The variation in immunoreactivity of fish/shellfish protein extracts after processing was assessed by rabbit IgG (anti-raw extracts) (figure 2) and by human IgE. The results showed that the IgG binding to sardine proteins was decreased in all processed extracts (figure 2). It was decreased by $19.8 \%$ in fried sardine, $27.2 \%$ in canned sardine, $29 \%$ in cooked sardine, $53.4 \%$ in marinated and $64.5 \%$ in fermented ones, compared with raw sardine. Concerning the ELISA results of the common pandora extracts under different treatments, results showed that there was a significant decrease in the binding of anti-IgG in all processed extracts (figure 2). This binding was reduced by $39.7 \%$, $58 \%, 41.8 \%$ and $49.8 \%$, respectively, in the fried, cooked, fermented and marinated common pandora. As regards shrimp extracts (figure 2), we noted a significant reduction by $69.2 \%$ in IgG binding in the fermented shrimp, as well as in the marinated shrimp, which was decreased by $37.2 \%$. No significant

Figure 1 - SDS-PAGE profiles of raw and processed fish protein extracts. A, sardine protein extracts (Sardina pilchardus); B, common pandora protein extracts (Pagellus erythrinus); $C$, shrimp protein extracts (Penaeus spp). Abbreviations: $M r$, markers of the molecular weights; PV, parvalbumin; TP, tropomyosin.

A

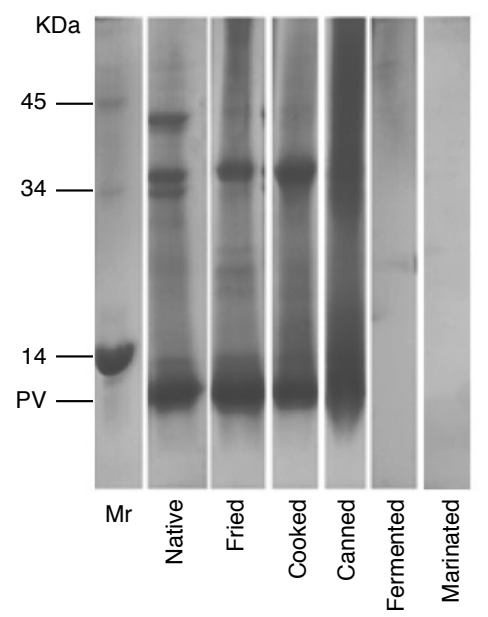

B

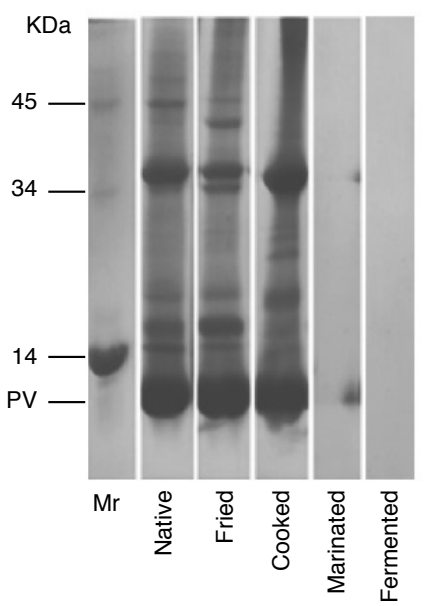

C

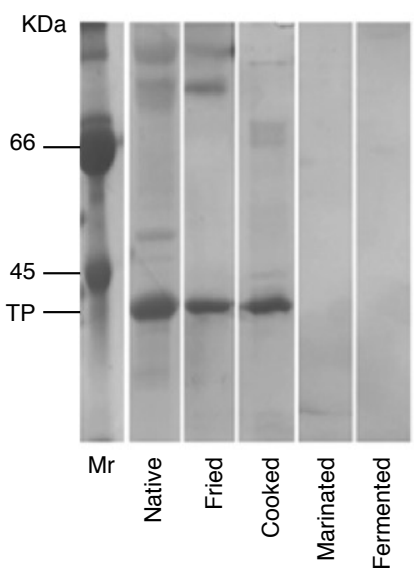


Figure 2 - Effect of industrial processing on the recognition of sardine, common pandora and shrimp extracts by rabbit IgG.

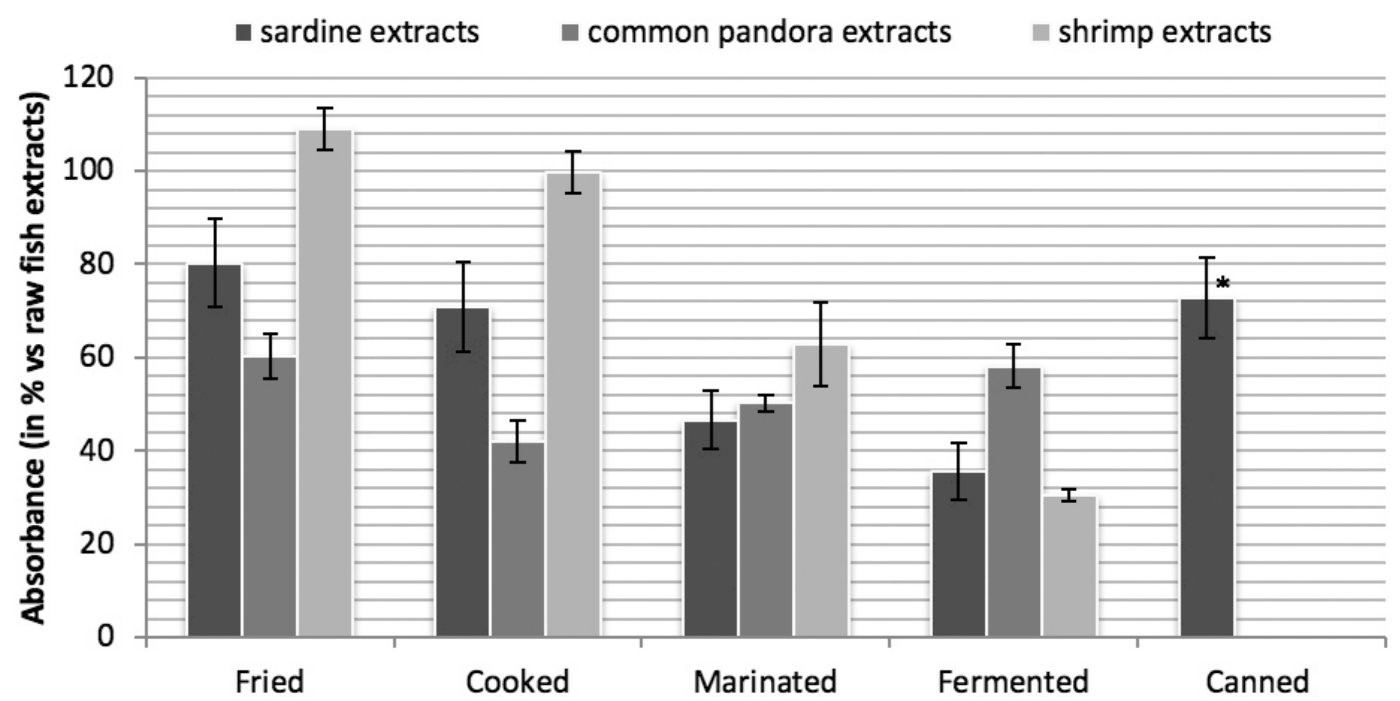

${ }^{1}$ Canned treatment was done just for sardine species.

change was observed in cooked extracts. In contrast, the fried treatment showed an increase in the IgG binding.

In general, all the processed sardine and common pandora extracts showed a decrease in the IgG binding. In sardine extracts, processing gradually decreased the capacity of the IgG binding in the following order: raw $>$ fried $>$ canned $>$ cooked $>$ marinated $>$ fermented, whereas in common pandora extracts, it was: raw $>$ fried $>$ fermented $>$ marinated $>$ cooked. However, in processed shrimp, it was in the order: raw $\sim$ cooked $>$ marinated $>$ fermented.

Effect of industrial processing on human IgE binding to fish proteins extracts using ELISA

ELISA was performed using selected human sera with high IgE binding levels to raw sardine $(\mathrm{n}=20)$, raw common pan-

Figure 3 - Effect of industrial processing on the recognition of sardine extracts by human IgE.

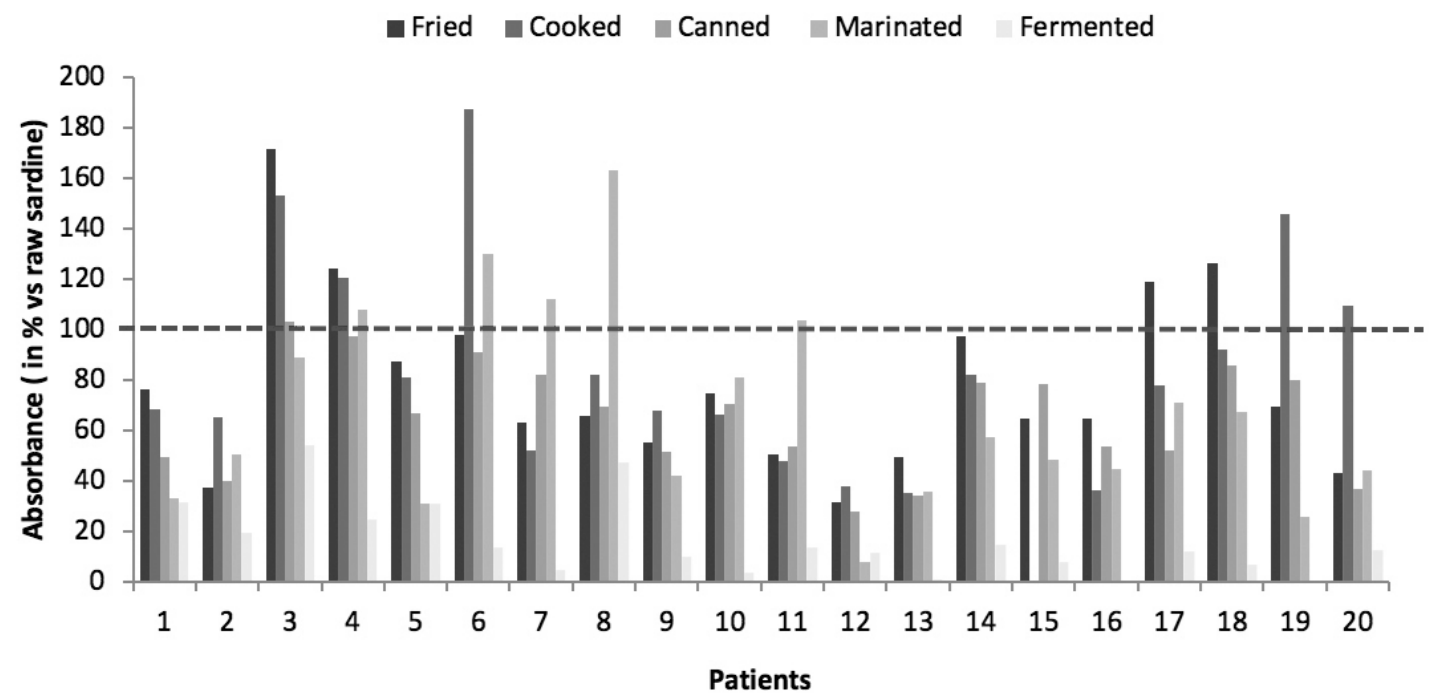


Figure 4 - Effect of industrial processing on the recognition of common pandora extracts by human IgE.

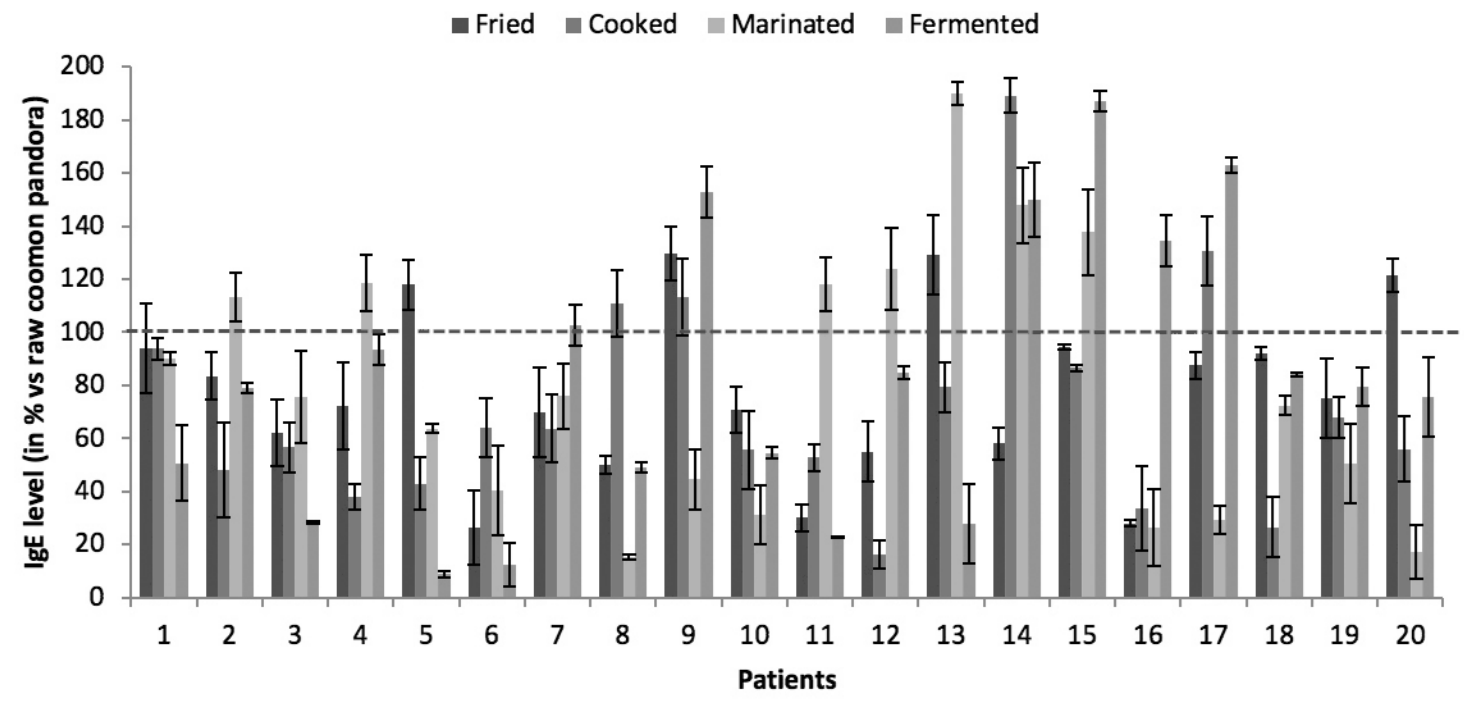

Figure 5 - Effect of industrial processing on the recognition of shrimp extracts by human IgE.

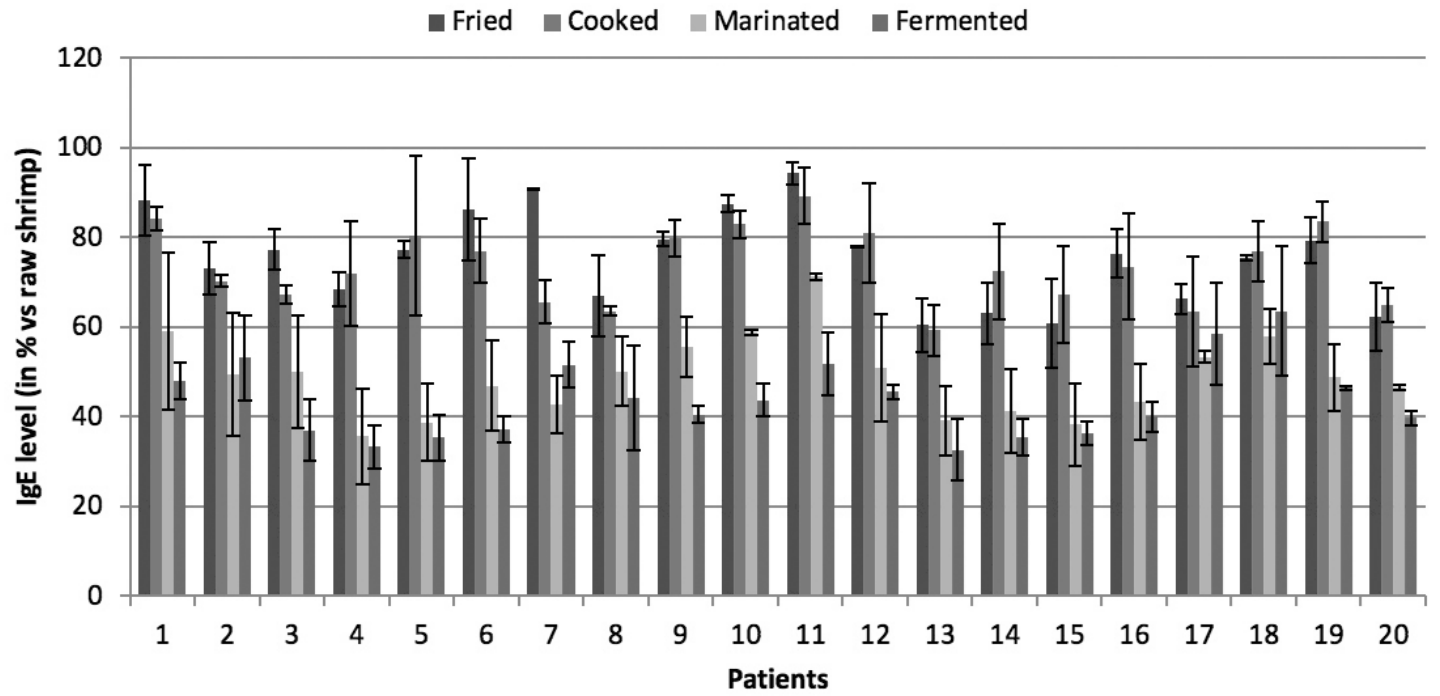

dora $(\mathrm{n}=20)$, and raw shrimp $(\mathrm{n}=20)$. These sera were used to estimate the binding variation of $\operatorname{IgE}$ to fish species under different processing (figures 3, 4 and 5). The recognition of raw fish species by human IgE was used as a control.

Figure 3 represents the distribution of specific IgE-binding levels to processed sardine proteins within a population of 20 patients. A marked decrease in the IgE binding was seen in the majority of patients. In this case, fermented sardine showed reduced IgE binding in all tested patients, with an average diminution of $84 \%$. Frying, cooking and canning products demonstrated decreased IgE binding in most sera $(16 / 20,15 / 20$ and $19 / 20$, respectively) with an average diminution of $35.6 \%, 40.4 \%$ and $36.8 \%$, respectively. In canned case, we observed that 8 patients exhibited more than $50 \%$ of IgE levels reduction. Similarly, marinade products showed decreased IgE binding in 15/20 patients, with an average diminution of $51.3 \%$. Increased IgE binding was seen in 3 products for two sera (no. 3,4 ), in 2 products for one serum 
(no. 6) and in 1 product for seven sera (no. 7, 8, 11, 17, 18, 19, 20).

In processed common pandora (figure 4), frying and cooking products both showed decreased IgE binding in 16/20 patients, with an average diminution of $34.4 \%$ and $44.9 \%$, respectively, while marinade and fermented products showed a reduction in the binding of $\operatorname{IgE}$ in $13 / 20$ and $14 / 20$ patients, respectively, with an average diminution of $51.4 \%$ and $46.4 \%$, respectively. Increased $\mathrm{IgE}$ binding was seen in 3 products for two sera (no. 9,14 ), in 2 products for three sera (no. 13, 15, 17), and in 1 product for nine sera (no. 2, 4, 5, 7, 8, 11, 12, 16, 20). In processed shrimp, figure 5 showed a decrease in the $\mathrm{IgE}$ binding to fried, cooked, marinated and fermented shrimp in all tested patients, with an average diminution of $24.4 \%, 26.3 \%, 51.1 \%$ and $56.3 \%$, respectively.

\section{Discussion}

The objective of this work was to study the effect of industrial processing on the allergenicity of three commonly consumed Moroccan fish species in Fez region (sardine, common pandora, shrimp). From human bank sera, 60 patients with high specific IgE levels to raw fish/shellfish extracts were selected, and used to estimate the binding variation of $\operatorname{IgE}$ to these products under several processing (frying, cooking, canning, marinade, and fermentation) using ELISA assay.

On SDS-PAGE profile of sardine and common pandora proteins, the parvalbumin was detected in fried and cooked extracts with almost the same band intensity as that in the raw extract, suggesting that the sardine and common pandora parvalbumin is still stable after frying and cooking. However, fermentation and marinade processing caused disappearance of parvalbumin band as well as all the additional bands. This suggests that parvalbumin is unstable on these processing methods, probably including degradation of fish proteins in small parts which were not revealed by SDS-PAGE. Similar conclusion by Sletten et al. (21) showed that parvalbumin was less stable in chemically processed fish types, fermented trout and some salted fish products. In canned sardine, loss of definable bands was observed on SDSPAGE profile protein, compared to the raw extract. Similarly, alteration of clearly definable protein bands in canned tuna and salmon has been previously reported $(21,22)$. Concerning SDSPAGE profile of shrimp proteins, the tropomyosin was seen in fried and cooked extracts, suggesting that shrimp tropomyosin is stable under those heating conditions (frying for $3 \mathrm{~min}$ and boiling for $5 \mathrm{~min}$ ). Whereas, this band protein disappeared when shrimp was marinated or fermented.

In a second part of the study, we have analyzed by ELISA the IgE immunoreactivity to processed sardine, common pandora and shrimp extracts using sera with high specific IgE levels to raw extracts. The results revealed that the fried and the cooked extracts showed a decrease in the IgE binding in the majority of patients, with an average reduction ranging from $25 \%$ to $45 \%$. Similarly, boiling and frying have been reported to reduce $\operatorname{IgE}$ binding properties of the fish allergens depending on fish species (23). On the other hand, we haven't observed any modification in fish/shellfish allergens bands by SDS-PAGE, so the low reduction observed by specific IgE analysis can be explained by modification of conformational $\mathrm{IgE}$ binding epitopes induced by heating conditions, since we observed approximately the same level of $\mathrm{IgE}$ reduction in boiling and frying processing. Previous works by our laboratory found that the IgE binding activity to isolate sardine parvalbumin, common pandora parvalbumin and shrimp tropomyosin can be reduced by heating, which was confirmed by dot blot assay showing that the intensity of spots became weak in all tested patients (16-18). This allowed us to consider that fish/shellfish allergen undergoes conformational changes depending on the heating load, resulting in a decrease in the binding ability to specific IgE. This suggests that the allergen epitopes recognized by human $\operatorname{IgE}$ are partially conformational. In contrast, increased IgE binding to processed extracts was seen in some patients, suggesting that some epitopes seem to be sequential. On these data, we concluded that boiling and frying can reduce the IgE binding to fish products, but they are not a solution for patients allergic to fish due to the low reduction in the IgE binding caused by these processes. This was confirmed by our questionnaire, showing that more than $60 \%$ of patients reporting sensitivity to fish declared allergy to fried and cooked fish products.

In canned sardine, our results demonstrated that canning products showed a high reduction in the human IgE binding in 95\% of patients, with an average diminution of $36.8 \%$, of which 8 patients exhibited more than $50 \%$ of IgE levels reduction. Similar results were described by different authors, who reported that canned tuna and salmon are less allergenic than raw and cooked fish, showing that the allergenicity of fish parvalbumin can be reduced during canning process. This decrease was demonstrated by ELISA-inhibition and oral challenges $(21,22,24)$. A recent descriptive study from Australia found that more than $21 \%$ of children allergic to salmon or tuna were able to tolerate the fish in canned form, indicating a reduction in skin prick test (SPT) size in most patients (25). Interestingly, Bernhisel-Broadbent et al. (22) showed that decreased fish allergenicity in canned tuna has important clinical implications, suggesting that canned products provide a nutritious, low fat, high protein food that can be recommended to many patients with fish allergies. Regarding our results and previous works, we could suggest that people allergic to fish could tolerate canned products. This was confirmed by our questionnaire, which revealed that only $39 \%$ of persons reporting fish allergy declared allergy to canned products compared to fried $(91 \%)$ and cooked $(67 \%)$ products. 
Regarding marinade processing, we noted that marinade fish products (sardine, common pandora and shrimp) showed a reduction in the binding of $\mathrm{IgE}$ in the most of patients, with an average diminution exceeding $50 \%$. By fermentation processing, results demonstrated that all tested patients showed a loss in their $\mathrm{IgE}$ reactivity to fermented sardine and shrimp products, with an average reduction of $84 \%$ and $56.3 \%$, respectively. In fermented common pandora, we noted a less effect than that observed with sardine and shrimp, with an average diminution of $46.4 \%$ marked in the most of patients. This decrease in the fish/shellfish allergenicity after fermentation processing can be explained by the action of microbial flora, causing proteolysis of fish/shellfish allergens and loss of IgE binding epitopes. During marinade fish processing, microorganisms may cause degradation of fish/shellfish proteins and therefore denaturation of the $\mathrm{IgE}$ binding epitopes, leading to a reduction in allergenicity. This was confirmed by SDS-PAGE, showing an absence of bands in marinated and in fermented extracts. These suggestions were confirmed by our data obtained before, showing a reduction of the allergenicity of sardine parvalbumin, common pandora parvalbumin and shrimp tropomyosin after enzymatic digestion, demonstrated by ELISA and dot blot analysis (16-18). Interestingly, previous studies showed that curing and fermentation processing resulted in a loss of IgE binding, suggesting that these processing are enzymatic processes which may induce changes in parvalbumin oligomers, either by altering the conformation or by direct cleavage of the IgE binding epitopes $(21,26)$. Furthermore, other works studying the effect of fermentation on the allergenicity of food proteins found that fermentation may destroy some antigenic epitopes, resulting in decreased allergenicity (27-30). This high action by marinade and fermentation processing was also observed with rabbit IgG, showing a high significant decrease in the IgG binding compared to frying and cooking. From these results, we concluded that marinade and fermentation processing can constitute an alternative for fish/shellfish allergic patients to consume fish/shellfish without allergic reactions, since the observed reduction was greater than cooking or frying.

\section{Conclusions}

In conclusion, our study has shown that the allergenicity of three commonly consumed Moroccan fish species can be reduced by different industrial processes (frying, cooking, canning, marinade and fermentation) with different degrees. Among these processing, marinade and fermentation seem to be more effective in the reduction of the IgE reactivity, compared to other processing.

\section{Acknowledgements}

This work was supported by grants of the Moroccan National Center for Scientific and techniques Research (CNRST) to
Najlae Mejrhit. We would like to thank the University Hospital Center of Fez as well as the laboratories of Fez for their assistance in finding patients.

\section{Conflict of interest}

The authors declare that they have no conflict of interest.

\section{References}

1. Pascual CY, Reche M, Fiandor A, Valbuena T, Cuevas T, Esteban MM. Fish allergy in childhood. Pediatr Allergy Immunol 2008; 19(7):573-9.

2. Soller L, Ben-Shoshan M, Harrington DW, Fragapane J, Joseph L, Pierre YS, et al. Overall prevalence of self-reported food allergy in Canada. J Allergy Clin Immunol 2012; 130(4):986-8.

3. Gupta RS, Springston EE, Warrier MR, Smith B, Kumar R, Pongracic J, et al. The prevalence, severity, and distribution of childhood food allergy in the United States. Pediatrics 2011; 128:9-17.

4. Kim JS, Ouyang F, Pongracic JA, Fang Y, Wang B, Liu X, et al. Dissociation between the prevalence of atopy and allergic disease in rural China among children and adults. J Allergy Clin Immunol 2008; 122:929-35.

5. Mejrhit N, Azdad O, Bousfiha A, Chokri, A, Ouahidi I, Aarab L. Evaluation of self-reported fish and shellfish allergy in schoolchildren in the Fez-Meknes Region and its relationship to breastfeeding. Rev Fr Allergol 2017; doi:10.1016/j.reval.2017.06.003 (in press).

6. Girija N, Rehbein H. Comparison of parvalbumin patterns from different fish species by isoelectric focusing of muscle extracts. Comp Biochem Physiol B 1988; 91(4):723-8.

7. Bugajska-Schretter A, Elfman L, Fuchs T, Kapiotis S, Rumpold, H, Valenta R, et al. Parvalbumin, a cross-reactive fish allergen, contains IgE-binding epitopes sensitive to periodate treatment and $\mathrm{Ca}$ 2+ depletion. J Allergy Clin Immunol 1998; 101(1):67-74.

8. Beale JE, Jeebhay MF, Lopata AL. Characterisation of purified parvalbumin from five fish species and nucleotide sequencing of this major allergen from Pacific pilchard, Sardinops sagax. Mol Immunol 2009; 46(15):2985-93.

9. Zhenxing L, Hong L, Limin C, Jamil K. Impact of irradiation and thermal processing on the immunoreactivity of shrimp (Penaeus vannamei) proteins. J Sci Food Agric 2007; 87(6):951-6.

10. Lopata AL, Lehrer SB. New insights into seafood allergy. Curr Opin Allergy Clin Immunol 2009; 9(3):270-7.

11. Gámez C, Zafra MP, Sanz V, Mazzeo C, Ibáńez MD, Sastre J, et al. Simulated gastrointestinal digestion reduces the allergic reactivity of shrimp extract proteins and tropomyosin. Food Chem 2015; 173:475-81.

12. Thomas K, Herouet-Guicheney C, Ladics G, Bannon G, Cockburn A, Crevel R, et al. Evaluating the effect of food processing on the potential human allergenicity of novel proteins: international workshop report. Food Chem Toxicol 2007; 45(7):1116-22.

13. Poms RE, Anklam E. (2004). Effects of chemical, physical, and technological processes on the nature of food allergens. J AOAC Int 2004; 87(6): 1466-74.

14. Rahaman T, Vasiljevic T, Ramchandran L. Effect of processing on conformational changes of food proteins related to allergenicity. Trends Food Sci Technol 2016; 49:24-34. 
15. Jiménez-Saiz R, Benedé S, Molina E, López-Exposito I. Effect of Processing Technologies on the Allergenicity of Food Products. Crit Rev Food Sci Nutr 2015; 55(13):1902-17.

16. Mejrhit N, Azdad O, El Kabbaoui M, Ouahidi I, Tazi A, Aarab L. Sensitivity of Moroccans to sardine parvalbumin and effect of heating and enzymatic treatments. Food Agric Immunol 2017; 28(6):1362-73.

17. Mejrhit N, Azdad O, Aarab L. Evaluation of the IgE reactivity of common pandora parvalbumin in a Moroccan population and action of heating and enzymatic treatments. Food Agric Immunol 2017; 1-12.

18. Mejrhit N, Azdad O, Chda A, El Kabbaoui M, Bousfiha A, Bencheikh R, et al. Evaluation of the sensitivity of Moroccans to shrimp tropomyosin and effect of heating and enzymatic treatments. Food Agric Immunol 2017; 28 (6):969-80.

19. Ouahidi I, El Hamsas AEY, Aarab L. Modulation of egg white protein allergenicity under physical and chemical treatments. Food Agric Immunol 2011; 22(1):57-68.

20. Bousfiha A, Aarab L. Effect of heat and enzymatic treatments on human $\operatorname{IgE}$ and rabbit IgG sensitivity to white bean allergens. Iran J Allergy Asthma Immunol 2013; 12 (4):304-11.

21. Sletten G, Van Do T, Lindvik H, Egaas E, Florvaag E. Effects of industrial processing on the immunogenicity of commonly ingested fish species. Int Arch Allergy Immunol 2010; 151(3):223-36.

22. Bernhisel-Broadbent J, Strause D, Sampson HA. Fish hypersensitivity. II. Clinical relevance of altered fish allergenicity caused by various preparation methods. J Allergy Clin Immunol 1992; 90:622-9.

23. Chatterjee U, Mondal G, Chakraborti P, Patra HK, Chatterjee BP. Changes in the allergenicity during different preparations of pomfret, hilsa, bhetki and mackerel fish as illustrated by enzyme-linked immunosorbent assay and immunoblotting. Int Arch Allergy Immunol 2006; 141(1):1-10.

24. Yamada S, Nolte H, Zychlinsky E. Identification and characterization of allergens in two species of tuna fish. Ann Allergy Asthma Immunol 1999; 82:395-400.

25. Turner P, Ng I, Kemp A, Campbell D. Seafood allergy in children: a descriptive study. Ann Allergy Asthma Immunol 2011; 106(6):494-501.

26. van Hengel AJ. Food allergen detection methods and the challenge to protect food allergic consumers. Anal Bioanal Chem 2007; 389:111-8.

27. Fotschki J, Szyc A, Wróblewska B. Immunoreactivity of lactic acid treated mare's milk after simulated digestion. J Dairy Res 2015; 82: 78-85.

28. Bu G, Luo Y, Zhang Y, Chen F. Effects of fermentation by lactic acid bacteria on the antigenicity of bovine whey proteins. J Sci Food Agric 2010; 90:2015-20.

29. Frias J, Song YS, Martínez-Villaluenga C, De Mejia EG, VidalValverde C. Immunoreactivity and amino acid content of fermented soybean products. J Agric Food Chem 2007; 56(1):99-105.

30. Sathe SK, Sharma GM. Effects of food processing on food allergens. Molecular nutrition and food research 2009; 53(8):970-8. 